\title{
Investigation on mechanical properties of aluminium 7075 - boron carbide - coconut shell fly ash reinforced hybrid metal matrix composites
}

\author{
*Balasubramani Subramaniam, Balaji Natarajan², Balasubramanian Kaliyaperumal', and Samson Jerold \\ Samuel Chelladurai ${ }^{2}$ \\ 1. Department of Mechanical Engineering, Sri Eshwar College of Engineering, Coimbatore - 641202, Tamilnadu, India \\ 2. Department of Mechanical Engineering, Sri Krishna College of Engineering and Technology, Coimbatore - 641008, India
}

\begin{abstract}
The present research work reports the fabrication and evaluation of the mechanical properties of hybrid aluminium matrix composites (HAMC). Aluminium 7075 (Al7075) alloy was reinforced with particles of boron carbide $\left(\mathrm{B}_{4} \mathrm{C}\right)$ and coconut shell fly ash (CSFA). Al7075 matrix composites were fabricated by stir casting method. The samples of Al7075 HAMC were fabricated with different weight percentages of $(0,3,6,9$ and $12 w t . \%)$ $\mathrm{B}_{4} \mathrm{C}$ and $3 w \mathrm{wt} \%$ of CSFA. The mechanical properties discussed in this work are hardness, tensile strength, and impact strength. Hardness of the composites increased $33 \%$ by reinforcements of $12 w t . \% \mathrm{~B}_{4} \mathrm{C}$ and $3 w t . \%$ CSFA in aluminium 7075 alloy. The tensile strength of the composites increased $66 \%$ by the addition of $9 w t . \% \mathrm{~B}_{4} \mathrm{C}$ and $3 \mathrm{wt} . \%$ CSFA in aluminium 7075 alloy. Further addition of reinforcements decreased the tensile strength of the composites. Elongation of the composites decreased while increasing $\mathrm{B}_{4} \mathrm{C}$ and CSFA reinforcements in the matrix. The impact energy of the composites increased up to $2.3 \mathrm{~J}$ with $9 \mathrm{wt} . \% \mathrm{~B}_{4} \mathrm{C}$ and $3 \mathrm{wt} . \% \mathrm{CSFA}$ addition in aluminium alloy. Further addition of reinforcement decreased the impact strength of the composites. The optical micrographs disclosed the homogeneous distribution of reinforcement particles ( $\mathrm{B}_{4} \mathrm{C}$ and CSFA) in Al7075 matrix. The homogeneously distributed $\mathrm{B}_{4} \mathrm{C}$ and CSFA particles added as reinforcement in the Al7075 alloy contributed to the improvement of hardness, tensile strength, and impact strength of the composites.
\end{abstract}

Key words: aluminium 7075; boron carbide; fly ash; casting; hardness; tensile strength; impact energy

CLC numbers: TG146.21

Document code: A

Article ID: 1672-6421(201806-449-08

\begin{abstract}
$\mathrm{A}$ luminium matrix composites (AMC) are used in advanced engineering applications such as automotive and aerospace industries and lightweight high strength applications to fulfil the emerging industrial requirements due to their good mechanical and tribological properties. A17075 reinforced with $\mathrm{B}_{4} \mathrm{C}$ composites produced by casting route showed the improvement in hardness and tensile properties ${ }^{[1-3]}$.

Zhang et al. ${ }^{[4]}$ reported that aluminium fly ash composites were manufactured by liquid reactive sintering powder metallurgy process with fly ash particles as intensifying phases. It was found that increasing the volume fraction of fly ash particles increased the hardness, modulus and wear resistance of aluminium composites. Dinaharan et al. ${ }^{[5]}$ investigated the
\end{abstract}

\section{*Balasubramani Subramaniam}

Male, born in 1984, Assistant Professor. His research interests mainly focus on the manufacturing and testing of metal matrix composites.

E-mail: balumecadcam@gmail.com

Received: 2018-08-17; Accepted: 2018-10-30 production and characterization of AA6061/18vol.\% rice husk ash in AMC using friction stir processing. The fractured rice husk ash particles revealed good interfacial bonding with the aluminium matrix. The tensile strength of the composite was improved due to the reinforcement of rice husk ash particles.

Kumar et al. ${ }^{[6]}$ evaluated the mechanical properties and wear behaviour of Al6061-SiC and Al7075- $\mathrm{Al}_{2} \mathrm{O}_{3}$ metal matrix composites. The reinforcement of the hard ceramic particles increases the micro hardness, tensile strength and density of the composites. Senthilvelan et al. ${ }^{[7]}$ investigated mechanical properties of Al7075 metal matrix composites reinforced with $10 \%$ volume fraction of $\mathrm{B}_{4} \mathrm{C}, \mathrm{SiC}$ and $\mathrm{Al}_{2} \mathrm{O}_{3}$ fabricated by stir casting process. The author reported that $\mathrm{A} 17075$ with $\mathrm{B}_{4} \mathrm{C}$ reinforced composite offered good mechanical properties compared to other particle reinforced composites.

Baradeswaran and perumal ${ }^{[8]}$ studied the mechanical and wear properties of $\mathrm{Al} 7075 / \mathrm{Al}_{2} \mathrm{O}_{3}$ /graphite hybrid composites. It was found that the mechanical properties increased with increasing the weight percentage of 
reinforced particles. Kenneth and Kazeem ${ }^{[9]}$ evaluated the mechanical and wear properties of the aluminium matrix hybrid composites reinforced with alumina, rice husk ash and graphite particles. The results showed that hardness of composites decreased with increasing weight percentage of rice husk ash and graphite. The graphite content had a significant role in the wear resistance but it decreased the mechanical properties while increasing the graphite weight percentage in aluminium alloy.

Reddy et al. ${ }^{[10]}$ reported that a hybrid composite provides better mechanical properties compared to pure aluminium. Al 6061 with different concentrations of silicon carbide and boron carbide were used to fabricate the hybrid composite by stir casting technique. The hybrid composite offered higher tensile, flexural strengths and hardness due to quantity of carbides present in the composites.

Jaswinder and Amit ${ }^{[1]}$ reviewed the feasibility and viability of developing low cost, high performance hybrid aluminium matrix composites used in heavy duty vehicles and wear resistance applications. Prasad et al. ${ }^{[12]}$ investigated the aluminium composites reinforced with rice husk ash (RHA) and $\mathrm{SiC}$ particulates. The results showed that the increasing reinforcement volume fraction of particles in aluminium alloys improved the hardness, tensile strength, yield strength and reduced the porosity of the hybrid composites, while the increased reinforcement particles in aluminium alloys decreased the elongation. Venkat \& Subramanian ${ }^{[13]}$ investigated the mechanical properties and wear behaviour of fly ash and graphite particles reinforced aluminium matrix composites. The addition of these reinforcements improved the mechanical properties and wear resistance of aluminium alloys.

Vijaya et al. ${ }^{[14]}$ evaluated the mechanical properties of LM25 aluminium matrix composite reinforced with alumina and boron carbide. The reinforcement of boron carbide provided excellent hardness and fracture toughness to aluminium alloy. Durga et al. ${ }^{[15]}$ optimized the mechanical properties of aluminium 7075 based hybrid metal matrix composites prepared by stir casting process. The authors reported that addition of the reinforcement improved the mechanical properties. Many researchers reported that addition of reinforcements significantly increased the mechanical properties of aluminium alloy such as hardness, tensile, impact and flexural strength ${ }^{[16-17]}$.

Aluminium matrix composites can be fabricated by liquid casting process or powder metallurgy technique. In the liquid casting process, particulates were well distributed in liquid metal before casting and solidification. These methods are cost effective method to produce particle reinforced composites. The stir casting process provides better bonding to the particles due to the stirring process in the manufacturing method. ${ }^{[18-20]}$. Karthikeyan and Nallusamy ${ }^{[21]}$ discussed the mechanical properties of aluminum 6063 reinforced with silicon carbide composites manufactured through stir casting method. The composites had good mechanical properties, low cost and good bonding in the crystal lattice. Rajesh et al. ${ }^{[22]}$ evaluated the mechanical properties of A17075 alloy reinforced with SiC particulates, and suggested that the composite could be considered as a good structural material in aerospace, transport, and automobile industries because of its excellent mechanical and wear properties.

In the current scenario, the least expensive and high performance materials necessitate more attention from researchers to develop hybrid composites because the hybrid composites have superior mechanical and tribological properties compared to the single reinforced composites, and the hybrid composites have more flexibility and reliability in the design of parts based on the reinforcement's combination and composition of material. The disposal of industrial and agriculture waste materials creates the environmental related issues. Therefore, it is of great significance if these waste materials can be recycled as green reinforcements in the fabrication of composite materials.

The literature review shows that currently very few research studies are carried out on the mechanical properties of aluminium alloy matrix reinforced with boron carbide and coconut shell fly ash hybrid composites. Therefore, the agriculture waste material of coconut shell fly ash was used as one of the reinforcements in this present work. The main aim of this research work is to investigate the effect of weight percentage of $\mathrm{B}_{4} \mathrm{C}$ and coconut shell fly ash (CSFA) reinforcement in aluminium 7075 alloy hybrid composites on the mechanical properties prepared by stir casting process.

\section{Materials and methods}

\subsection{Materials}

Al7075 alloy was purchased in the form of cylindrical rods and its chemical composition is shown in Table 1. The particles of boron carbide with an average particle size of about $75 \mu \mathrm{m}$ (Fig.1) and coconut shell fly ash as secondary reinforcement were used as the reinforcements for developing the hybrid composites. Aluminium was used as matrix because of its light weight, high strength, durability and good machinability.

Table 1: Chemical composition of Al7075 aluminium alloy (wt.\%)

$\begin{array}{cccccccccc}\mathrm{Si} & \mathrm{Fe} & \mathrm{Cu} & \mathrm{Mn} & \mathrm{Mg} & \mathrm{Cr} & \mathrm{Zn} & \mathrm{Ti} & \mathrm{Zr} & \mathrm{Al} \\ 0.041 & 0.064 & 1.812 & 0.005 & 1.681 & 0.002 & 6.012 & 0.041 & 0.148 & \text { Bal. }\end{array}$

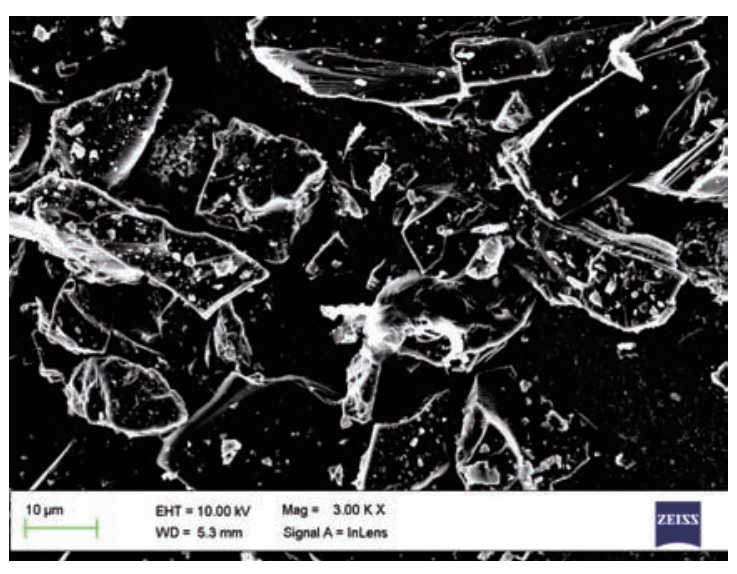

Fig. 1: SEM morphology of boron carbide particles 


\subsection{Preparation of coconut shell fly ash}

The coconut shell was easily available in the agricultural area and disposal of the waste is a major problem in the world. The use of coconut shell waste as reinforcement can reduce the cost of material and clean the environment. The coconut shell fly ash was prepared through rubbing the coconut shell by emery sheet which removed the impurities on the outside of the shell. Cleaned coconut shells are shown in Fig. 2. Subsequently, the coconut shell was dried in sunlight for 2-3 days to remove the moisture content. The dried coconut shells were sliced into small pieces and kept inside a furnace and heated for $2 \mathrm{~h}$ when the temperature was maintained at $400{ }^{\circ} \mathrm{C}$. The burnt particles were subjected to a heat treatment at $800{ }^{\circ} \mathrm{C}$ for about $10 \mathrm{~h}$ to remove the carbonaceous material.

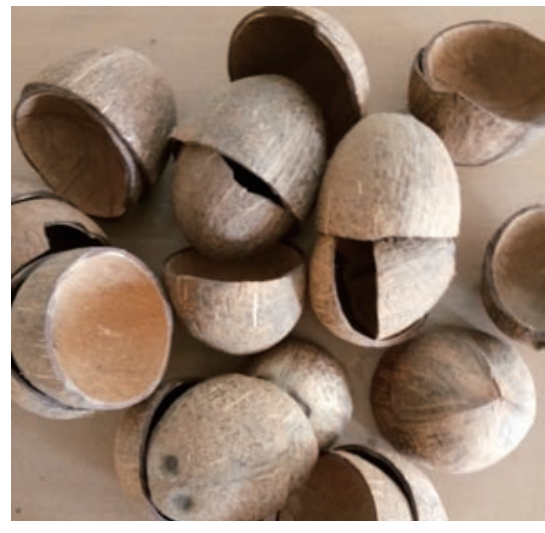

Fig. 2: Cleaned coconut shell

The chemical composition of coconut shell fly ash particles was analyzed by optical emission spectroscopy and the results are presented in Table 2. The sieved coconut shell fly ash particles with an average size of about $62 \mu \mathrm{m}$ as shown in Fig. 3 were used to produce the composites. The crystallographic form of coconut shell powder after baking at high temperature is crystalline as shown in Fig. 4.

Table 2: Chemical compositions of coconut shell fly ash and their weight percentage

$\begin{array}{cccccccc}\mathrm{SiO}_{2} & \mathrm{Al}_{2} \mathrm{O}_{3} & \mathrm{Fe}_{2} \mathrm{O}_{3} & \mathrm{MgO} & \mathrm{Na}_{2} \mathrm{O} & \mathrm{CaO} & \mathrm{ZnO} & \mathrm{MnO} \\ 45.36 & 21.82 & 18.58 & 12.32 & 0.73 & 0.67 & 0.32 & 0.20\end{array}$

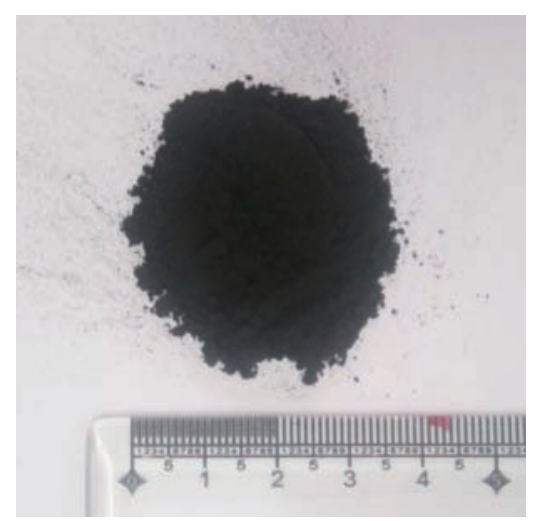

Fig. 3: Coconut shell fly ash powder

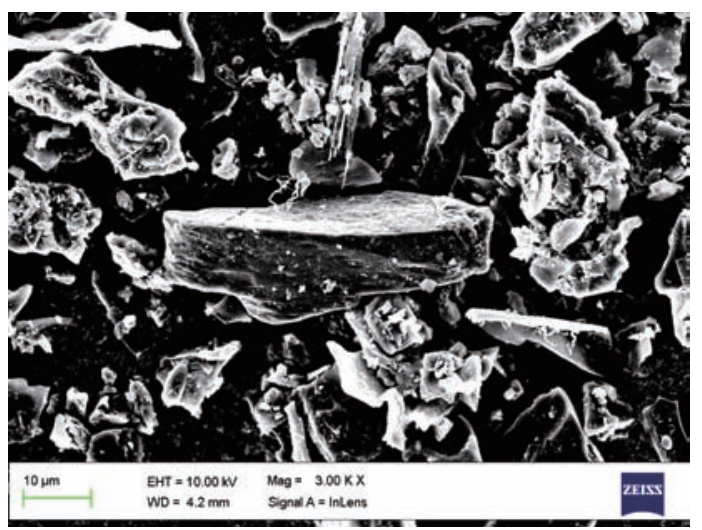

Fig. 4: SEM morphology of coconut shell fly ash powder

\subsection{Fabrication method}

Stir casting experimental setup as shown in Fig. 5 was used to prepare A17075 hybrid composites. Aluminium metal matrix composite preparation process commenced with the matrix material of A17075 alloy and proportions of varying cumulative weight percentage viz $0,3,6,9,12$ and $15 \mathrm{wt} . \%$ of $\mathrm{B}_{4} \mathrm{C}$ and CSFA, as shown in Table 3. A17075 alloy was melted in the furnace and heated up to $780{ }^{\circ} \mathrm{C}$. The reinforcing materials $\left(\mathrm{B}_{4} \mathrm{C}\right.$ and CSFA) were initially preheated to $300{ }^{\circ} \mathrm{C}$ before charging into the melt. The melting furnace temperature was measured by inserted thermocouples. The preheated reinforcing materials were added into the A17075 alloy based on weight percentage as mentioned in Table 3.

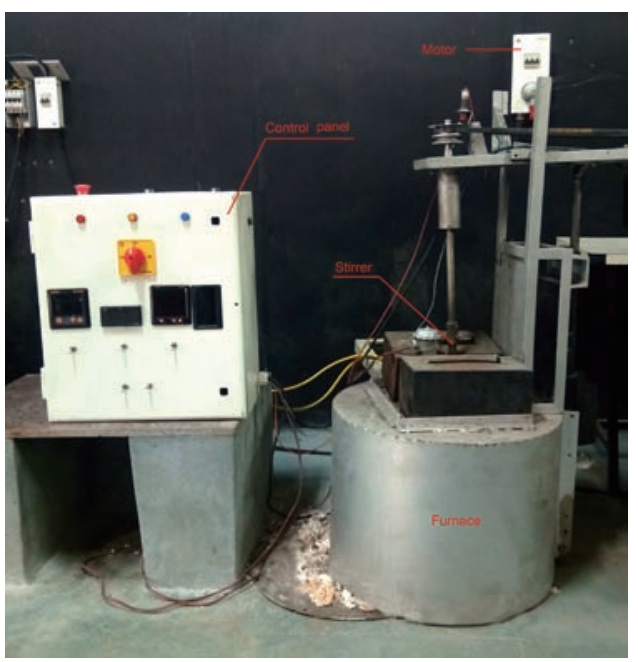

Fig. 5: Stir casting setup for fabricating Al7075 based hybrid composites

Table 3: Varying weight percentage of $\mathrm{B}_{4} \mathrm{C}$ and CSFA in Al7075 alloy

\begin{tabular}{ccccc} 
Sample No. & $\begin{array}{c}\mathbf{B}_{4} \mathbf{C} \\
(w t . \%)\end{array}$ & $\begin{array}{c}\text { CSFA } \\
\text { (wt.\%) }\end{array}$ & $\begin{array}{c}\text { Cumulative } \\
\text { of } \mathbf{B}_{4} \mathbf{C}+\text { CSFA } \\
\text { (wt. \%) }\end{array}$ & $\begin{array}{c}\text { Al7075 } \\
\text { alloy }\end{array}$ \\
\hline 1 & 0 & 0 & 0 & \\
2 & 0 & 3 & 3 & \\
3 & 3 & 3 & 6 & Bal. \\
4 & 6 & 3 & 9 & \\
5 & 9 & 3 & 12 & \\
6 & 12 & 3 & 15 &
\end{tabular}


The mixture of reinforcing particles was stirred at $800 \mathrm{rpm}$ for $10 \mathrm{~min}$ by means of a coupled electric stirrer with motor. Jiang and Wang reported ${ }^{[24]}$ that the maximum stirring time resulted in better bonding between particles and aluminium which increased the strength of the composites. In this work, stirring process was continued until the proper mixing of the reinforcements in the aluminium alloy. Potassium titanium fluoride was also added into the melt to increase the wettability and interfacial bonding between the matrix and reinforcements. This flux was also used to remove the oxide film in the aluminium surface.

The cylindrical die was made up of H11 die steel and preheated to $225^{\circ} \mathrm{C}$. The mixture of the composite melt was poured into the preheated die to produce the casting with $10 \mathrm{~mm}$ diameter and $100 \mathrm{~mm}$ height. The specimens were cut from the casting by wire cut electrical discharge machining. The machined specimens were used to check the microstructure, hardness, tensile strength, and impact energy.

\subsection{Microscopic examination}

The microstructures were examined using an image analyzer to study the distribution of $\mathrm{B}_{4} \mathrm{C}$ and CSFA particles in the matrix. The specimens with a size of $40 \mathrm{~mm} \times 40 \mathrm{~mm} \times 10 \mathrm{~mm}$ were polished and mirror finished specimens were used to obtain micrographs.

\subsection{Mechanical properties}

The effect of changes in the reinforcement particles in different weight percentage of $\mathrm{B}_{4} \mathrm{C}$ and CSFA with $\mathrm{A} 17075$ composites were analyzed by determining the mechanical properties of the specimens viz hardness, tensile strength and impact energy. The hardness test was performed as per ASTM E10-07 standards using Brinell hardness testing machine with $10 \mathrm{~mm}$ ball indenter and $500 \mathrm{~kg}$ load.

The hardness was measured using a test specimen of $40 \mathrm{~mm}$ $\times 40 \mathrm{~mm} \times 10 \mathrm{~mm}$. The hardness values were measured in three different places in each specimen and the average value of the hardness is presented in the paper. The composite specimens for determining the tensile strength were prepared according to the ASTM E8-M04 standard ${ }^{[27]}$. The standard dimensions of tensile test specimen (6 mm of thickness, $12 \mathrm{~mm}$ of width, 40 $\mathrm{mm}$ of the gauge length with $30 \mathrm{~mm}$ gripping surface length) are shown in Fig. 6. The tensile strength was measured using a computerized universal testing machine HITECH TUE-C-1000.

The impact test specimens were prepared as per the ASTM-E23 standard. The standard size of impact specimen is $55 \mathrm{~mm} \times 10 \mathrm{~mm} \times 10 \mathrm{~mm}$ with a Charpy V notch. The test was conducted at room temperature and the impact energy values were measured for three specimens in each composition to obtain the average value. The fracture surfaces were observed on a field emission scanning electron microscope.

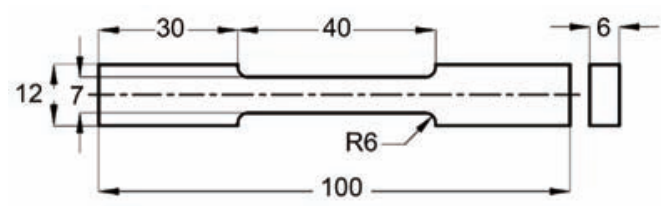

Fig. 6: Tensile specimen as per ASTM E8 M-04

\section{Results and discussion}

\subsection{Microstructure}

Figure 7(a-b) shows the microstructure of A17075 alloy reinforced with B4C-CSFA hybrid composite. The results show that the reinforced particles are randomly oriented, and their distribution in the matrix is uniform. Figure 7(b) shows the minimum porosity and good bond strength between the $\mathrm{B}_{4} \mathrm{C}$-CSFA reinforced particles and the Al7075 matrix. This result shows that multiple enhancers reduce the porosity in the composite.
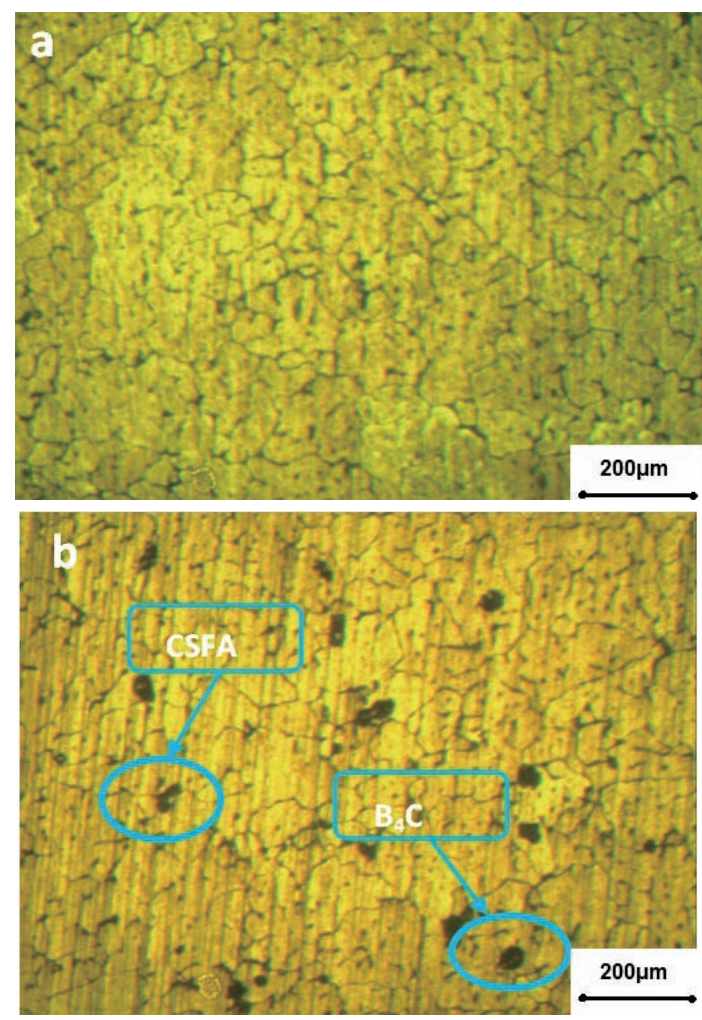

Fig. 7: Optical micrographs of Al7075 alloy with wt.\% of reinforcements of $\mathrm{B}_{4} \mathrm{C}$ and CSFA composites: (a) $0 w t . \%$ (b) $12 w t . \% B_{4} C$ and $3 w t . \%$ CSFA

\subsection{Hardness}

Hardness of A17075 reinforced with $\mathrm{B}_{4} \mathrm{C}$-CSFA hybrid composite is shown in Fig. 8. The hardness values were measured at three locations in each sample and the average of three hardness values for each sample is listed in Table 4. It indicates that hardness of composite material increases with addition of $\mathrm{B}_{4} \mathrm{C}$ and CSFA reinforcement in aluminium alloy. The increasing wt. $\%$ of reinforcement gives increment value of hardness from 127.5 BHN to $169.5 \mathrm{BHN}$. The multiple reinforcements contribute to minimizing the porosity and fine grain structure of particles as well as creating the resistance to plastic deformation which increases the hardness of hybrid composites. This is due to the reinforcement of $\mathrm{B}_{4} \mathrm{C}$ and CSFA particles in the aluminium matrix composites. The maximum hardness was $169.5 \mathrm{BHN}$ by cumulative reinforcement of $15 \mathrm{wt} . \% \mathrm{~B}_{4} \mathrm{C}$ and CSFA particles in aluminum alloy. Similar results were found in the fly ash particle reinforced composites, which improved hardness of the aluminum matrix composite ${ }^{[28-31]}$. 


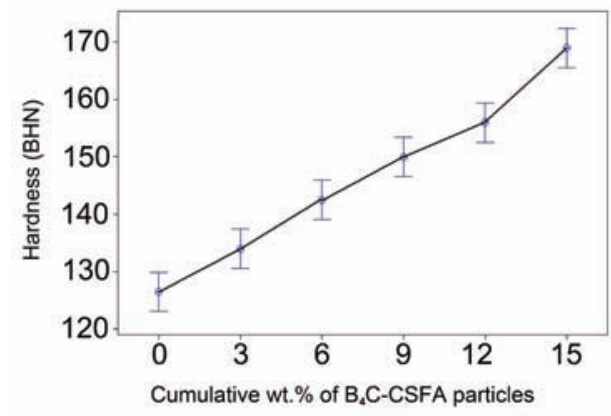

Fig. 8: Variation of hardness of hybrid composites

\subsection{Tensile strength}

Two tensile test values are shown in Table 4. In this research, the test results show the improvement in the tensile strength with increasing the weight percentage of $\mathrm{B}_{4} \mathrm{C}$-CSFA. The composite with 9 wt. $\% \mathrm{~B}_{4} \mathrm{C}$ and $3 \mathrm{wt} . \%$ CSFA had maximum tensile strength up to $189 \mathrm{MPa}$, which was $66 \%$ higher than the unreinforced $\mathrm{Al}$ 7075 matrix alloy. The tensile strength of the hybrid composites against wt. $\%$ of $\mathrm{B}_{4} \mathrm{C}-\mathrm{CSFA}$ are plotted and shown in Fig. 9. It can be seen from Fig. 9 that the addition of weight percentage of reinforcements increases the tensile strength up to $9 \mathrm{wt} . \%$ $\mathrm{B}_{4} \mathrm{C}$ and $3 \mathrm{wt} . \%$ CSFA, and further addition of reinforcement reduces the tensile strength of composites. The presence of CSFA and higher weight percentage of $\mathrm{B}_{4} \mathrm{C}$ increased the strengthening effect and absorbed load in composite materials.
Earlier research results also revealed ${ }^{[28,30]}$ that the aluminium alloy with reinforcement particles like boron carbide and fly ash reinforcement offered maximum tensile strength as compared to the unreinforced $\mathrm{Al}$ alloy.

The reinforcement of particles induced the higher strength and offered more resistance to the tensile stresses ${ }^{[22,28]}$. The load transfer from the matrix to the reinforcement particles gives maximum tensile strength of composites.

Ductility of the composites was obtained by percentage of elongation as shown in Table 4. It was observed that the elongation of all the produced composites was within the range of $9.8 \%$ to $13.8 \%$ and there is a consistent trend in decreasing the ductility of composites. However, results revealed that ductility of composites decreased while adding the reinforcements in the matrix

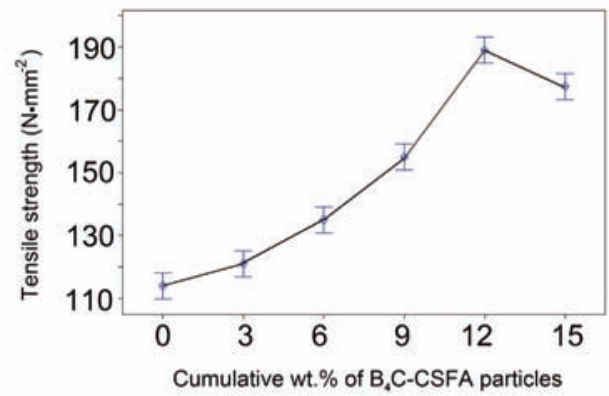

Fig. 9: Variation of tensile strenth of hybrid composites

Table 4: Mechanical properties of Al7075 alloy with varying weight percentage of $\mathrm{B}_{4} \mathrm{C}$ and constant $3 \mathrm{wt} . \%$ of $\mathrm{CSFA}$ particulates

\begin{tabular}{|c|c|c|c|c|c|c|}
\hline Sample No. & Wt. $\%$ of $\mathbf{B}_{4} \mathbf{C}$ & Wt. $\%$ of CSFA & $\begin{array}{l}\text { Hardness } \\
\text { (BHN) }\end{array}$ & $\begin{array}{l}\text { Ultimate tensile } \\
\text { strength } \\
\text { (MPa) }\end{array}$ & $\begin{array}{c}\text { Elongation } \\
(\%)\end{array}$ & $\begin{array}{c}\text { Energy } \\
\text { absorbed } \\
(\mathrm{J})\end{array}$ \\
\hline 1 & 0 & 0 & 127 & 114 & 13.8 & 0.6 \\
\hline 2 & 0 & 3 & 134 & 121 & 13.5 & 1.3 \\
\hline 3 & 3 & 3 & 142 & 135 & 12.8 & 1.8 \\
\hline 4 & 6 & 3 & 149 & 155 & 12.3 & 2.1 \\
\hline 5 & 9 & 3 & 155 & 189 & 10.8 & 2.3 \\
\hline 6 & 12 & 3 & 169 & 177 & 9.8 & 2.0 \\
\hline
\end{tabular}

The composite containing 12wt.\% $\mathrm{B}_{4} \mathrm{C}$ and 3wt.\% CSFA had the lowest value in the percentage of elongation among all of the composite materials produced. The interfacial bonding between reinforcement and matrix forms the micro pores, initiating the propagation which caused fracture of composites. It reduced the plasticity behaviour of hybrid composites.

Appearances of fracture surfaces for tensile specimens were examined by field emission scanning electron microscope (Fig.10). The ductile fracture occurred in the composites due to microvoids leads to the crack initiation and formation (Fig. 10a).

The ductile fracture is described by finer dimple formation in the fracture surface. The brittle fracture occurred in the composites due to transgranular grain boundary movement and was caused by transgranular cleavage formations. From the SEM results in Fig. 10, it was observed that composite specimens failed by combination of ductile and brittle fracture. The fracture surfaces of SEM image results revealed that micro voids created the initial cracks, and propagation of these cracks resulted in ductile fracture. The addition of $\mathrm{B}_{4} \mathrm{C}$-CSFA particles in the A17075 aluminium matrix composites was initiatives of cleavage planes at the grain boundaries. It led to the brittle fracture in the specimens because of the applied tensile force in the composite materials. This is also evident from the previous work ${ }^{[32]}$ in the fracture surface that the resistance properties of the hybrid composites to tensile force varied because of its crack initiation and propagation which results in brittle and ductile fracture. 

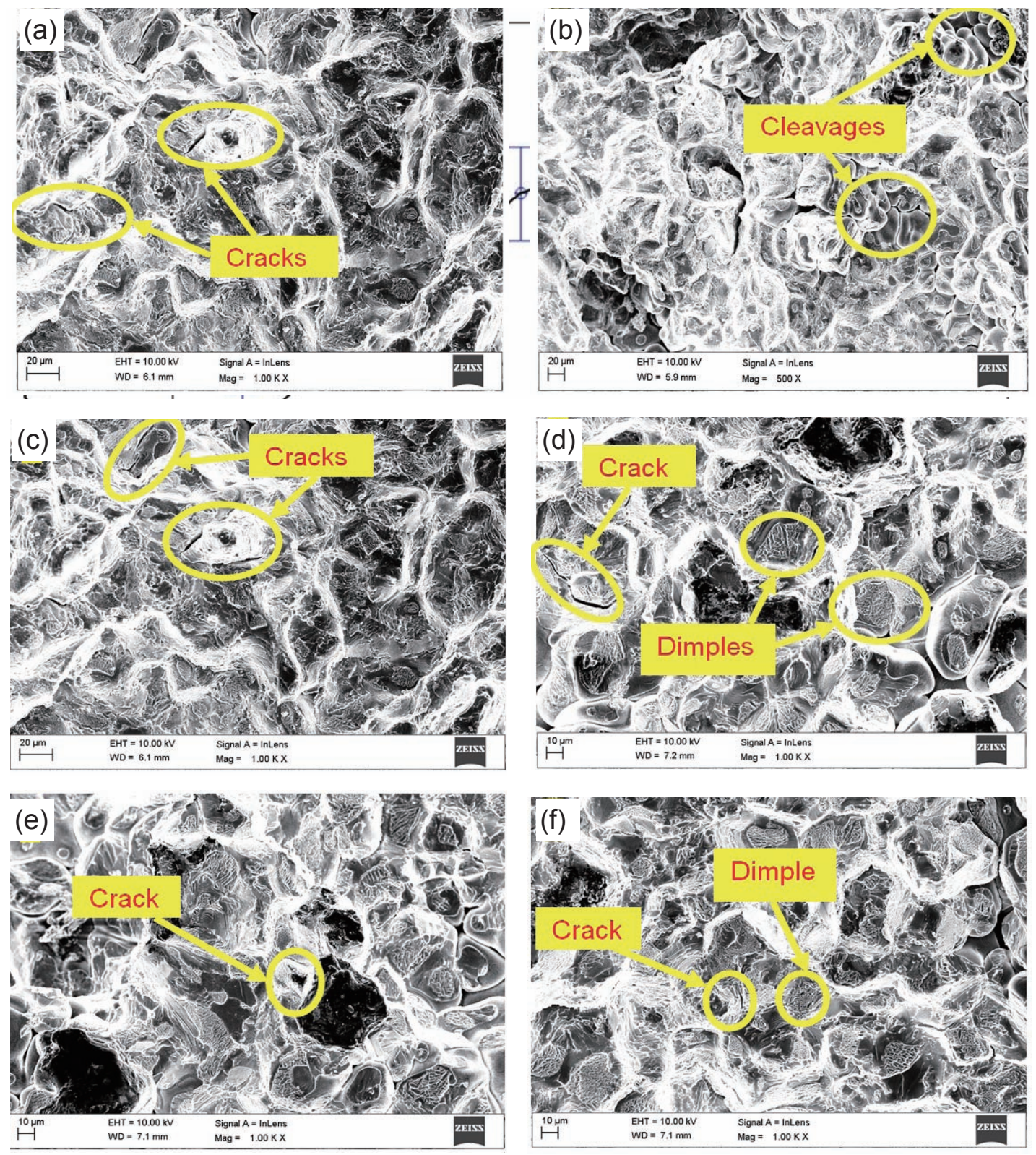

Fig. 10: FESEM photographs of tensile fracture surface of Al7075 alloy with cumulative wt. $\%$ of reinforcements $\mathrm{B}_{4} \mathrm{C}$ and CSFA: (a) 0wt\%, (b) 3wt.\%, (c) 6wt.\%, (d) 9wt.\%, (e)12wt.\%, (f) $15 w t . \%$

\subsection{Impact strength}

The impact energy of composites against the cumulative weight percentage of $\mathrm{B}_{4} \mathrm{C}$-CSFA reinforcements is plotted and shown in Fig.11. It was found that increasing the cumulative weight percentage of $\mathrm{B}_{4} \mathrm{C}$-CSFA reinforcement from 3 to $12 \mathrm{wt} . \%$ increased the impact energy. Further addition of reinforcements reduced the impact energy due to the micro pores in the composites and crack initiation in the reinforcements-matrix interfaces, which resulted in the failure at the earlier stage.

It was concluded that the composites strengthening can be improved by adding the reinforcements.

The fracture surfaces of broken impact specimens were observed by FESEM, as shown in Fig. 12. The fracture surface of A17075 alloy (Fig.12a) shows the presence of cracks and dimples in most of the regions. Figure $12 \mathrm{~b}$ shows heterogeneous dispersion of CSFA particles in the matrix formed as clusters and this formation reduced the matrix-reinforcement bonding

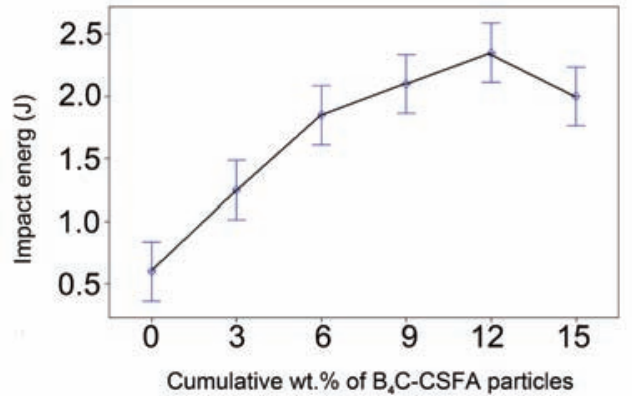

Fig. 11: Variation of impact energy of composites

in the composites. It was observed that cracks were initiated at high stress concentration areas leading to brittle fracture. Figure12(c-f) revealed that the distribution of reinforcement particles $\mathrm{B}_{4} \mathrm{C}$ and CSFA appears to be homogeneous without clustering or agglomeration. Good interfacial bonding between the matrix and reinforcement led to higher impact toughness. 

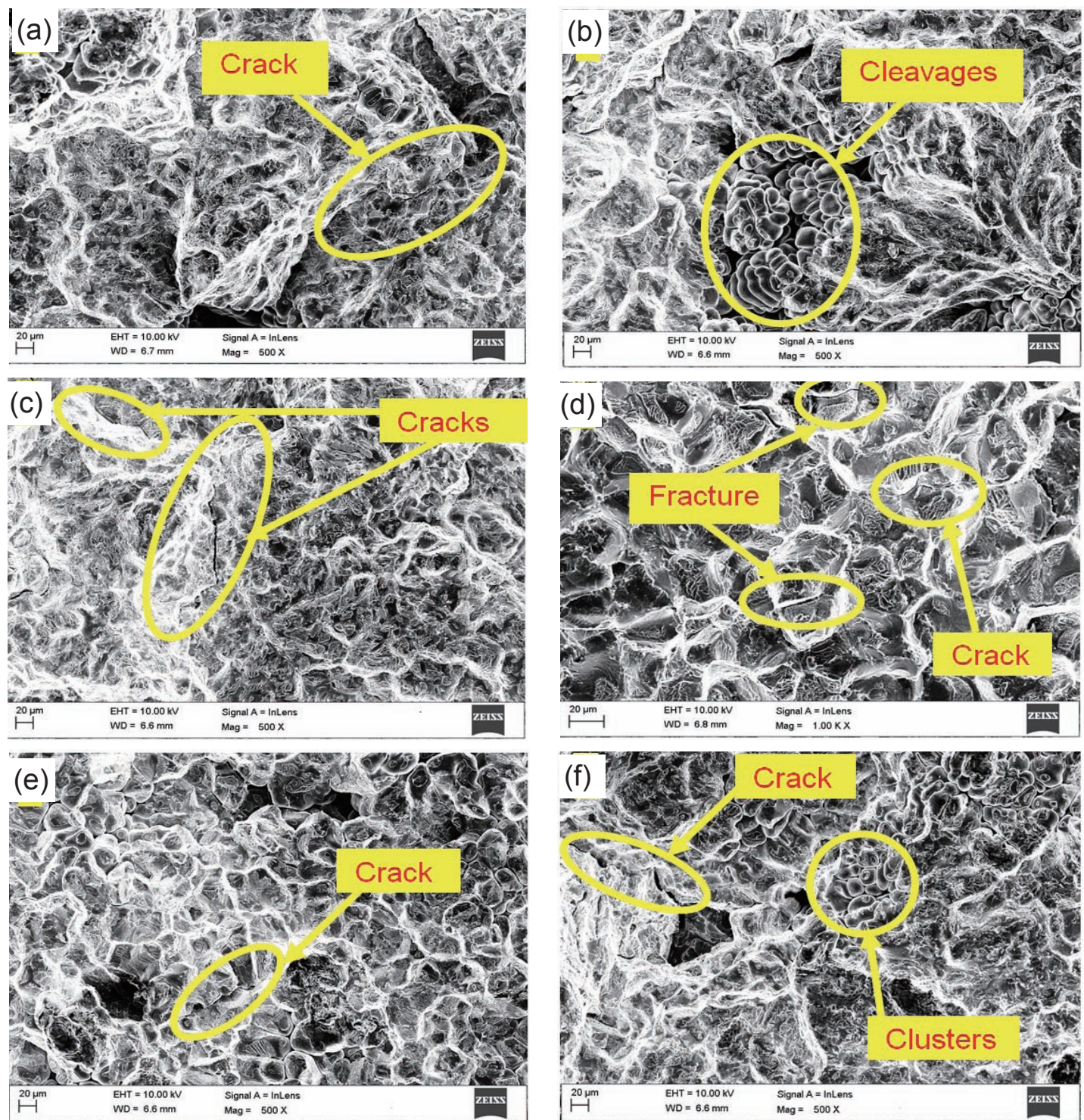

Fig. 12: FESEM photographs of impact fracture surface of Al7075 alloy with cumulative wt. $\%$ of reinforcements $B_{4} C$ and CSFA: (a) 0 wt.\%, (b) 3wt.\%, (c) $6 w t . \%$, (d) $9 w t . \%$, (e) $12 w t . \%$, (f) $15 w t . \%$

Even though there was less debonding in the matrix and reinforcement, the fracture was dominated by particle cracks. The fracture occurred in the particles' surface and the reinforcement particles acted as a barrier to crack growth and propagation. The results show that improvement of this resistance increased the impact toughness. It also led to brittle intergranular crack growth and the transgranular cleavages at the grain boundary. The reinforcement particles formed stronger interfaces with the matrix and it resisted the fracture. The fracture toughness of composites is based on the energy absorbed by the specimen of fracture. This is also evident from the previous research work ${ }^{[33]}$ in the fracture toughness that cracks initiated at the interfaces of matrix and reinforcements caused fracture of composites. In the aluminium matrix composites reinforced with $\mathrm{B}_{4} \mathrm{C}$-CSFA particles, fracture toughness is higher due to high plastic deformation energy in the stress concentration surfaces.

\section{Conclusions}

(1) The microstructure results show uniform distribution of the reinforcements and minimum level of porosity in the composites. The manufacturing of low cost hybrid aluminium matrix composites using coconut shell fly ash as a complementing reinforcement with boron carbide has a great advantage because of its higher mechanical properties exhibited by the manufactured hybrid composites.

(2) Hardness of composites increases with increasing reinforcement content in the matrix. The maximum hardness (169.5 BHN) of composites is observed for the $12 \mathrm{wt} . \% \mathrm{~B}_{4} \mathrm{C}$ and 3wt.\% CSFA composite.

(3) Tensile strength of composites increases by the addition of reinforcement particles $\mathrm{B}_{4} \mathrm{C}$ and CSFA in the aluminium7075. The maximum tensile strength $(189 \mathrm{MPa})$ is obtained for 9 wt. $\% \mathrm{~B}_{4} \mathrm{C}$ and 3 wt.\% CSFA composite that increased by $66 \%$ compared with the unreinforced aluminium 7075 . The ductility of the composites decreases with increasing the weight percentage of reinforcement particles.

(4) Fracture surface of tensile test specimens shows dimple formation in the composites. The multiple reinforcements result in the reduction in porosity level and better interface bonding 
which offer resistance to crack propagation.

(5) Impact energy of composites is increased by increasing the reinforcement content in the matrix. Maximum impact energy of $2.3 \mathrm{~J}$ is achieved for $9 \mathrm{wt} . \% \mathrm{~B}_{4} \mathrm{C}$ and $3 \mathrm{wt} . \% \mathrm{CSFA}$ composite. The impact energy decreases with further addition of reinforcement particles in the matrix due to micro pores, crack initiation in the composites which bring about premature failure in the composites.

(6) Fracture surface of impact test specimens shows that the fracture occurred in the particle surface and the reinforcement particles acts as a barrier against crack propagations. Also, reinforcement particles in the matrix absorbe load during the impact test, which resists fracture.

\section{References}

[1] Shalaby E A, Churyumov A Y, Solonin A N, et al. Preparation and characterization of hybrid $\mathrm{A} 359 /\left(\mathrm{SiC}+\mathrm{Si}_{3} \mathrm{~N}_{4}\right)$ composites synthesized by stir/squeeze casting techniques. Materials Science and Engineering: A, 2016, 674: 18-24

[2] Baradeswaran A, Perumal A E. Influence of $B_{4} C$ on the tribological and mechanical properties of Al $7075-B_{4} C$ composites. Composites Part B: Engineering, 2013, 54: 146-152.

[3] Surappa M K. Aluminium matrix composites challenges and opportunities. Sadhana, 2003, 28(1-2): 319-334.

[4] Zhang X F, Wang D J, Xie G. Manufacturing of aluminum/fly ash composite with liquid reactive sintering technology. Acta Metallurgica Sinica English Letters, 2009, 15(5): 465-470.

[5] Dinaharan I, Kalaiselvan K, Murugan N. Influence of rice husk ash particles on microstructure and tensile behavior of AA6061 aluminum matrix composites produced using friction stir processing. Composites Communications, 2017, 3: 42-46.

[6] Kumar G V, Rao C S P, Selvaraj N, et al. Studies on Al6061-SiC and $\mathrm{Al} 7075-\mathrm{Al}_{2} \mathrm{O}_{3}$ metal matrix composites. Journal of Minerals and Materials Characterization and Engineering, 2010, 9(1): 43-55.

[7] Senthilvelan T, Gopalakannan S, Vishnuvarthan $S$, et al. Fabrication and characterization of $\mathrm{SiC}, \mathrm{Al}_{2} \mathrm{O}_{3}$ and $\mathrm{B}_{4} \mathrm{C}$ reinforced $\mathrm{Al}-\mathrm{Zn}-\mathrm{Mg}-\mathrm{Cu}$ alloy (Al7075) metal matrix composites: A study. Advanced Materials Research, 2013, 622: 1295-1299.

[8] Baradeswaran A, Perumal A E. Study on mechanical and wear properties of $\mathrm{Al} 7075 / \mathrm{Al}_{2} \mathrm{O}_{3} / \mathrm{graphite}$ hybrid composites. Composites Part B: Engineering, 2014, 56: 464-471.

[9] Alaneme K K, Sanusi K O. Microstructural characteristics mechanical and wear behaviour of aluminium matrix hybrid composites reinforced with alumina, rice husk ash and graphite. Engineering Science and Technology, an International Journal, 2015, 18(3): 416-422.

[10] Reddy P S, Kesavan R, Ramnath B V. Investigation of mechanical properties of aluminium 6061-silicon carbide, boron carbide metal matrix composite. Silicon, 2018, 10(2): 495-502.

[11] Singh J, Chauhan A. Characterization of hybrid aluminum matrix composites for advanced applications-A review. Journal of Materials Research and Technology, 2016, 5(2): 159-169.

[12] Prasad D S, Shoba C, Ramanaiah N. Investigations on mechanical properties of aluminum hybrid composites. Journal of Materials Research and Technology, 2014, 3(1): 79-85.

[13] Venkat Prasat S, Subramanian R. Tribological properties of AISi10Mg/ fly ash/graphite hybrid metal matrix composites. Industrial Lubrication and Tribology, 2013, 65(6): 399-408.

[14] Ramnath B V, Elanchezhian C, Jaivignesh M, et al. Evaluation of mechanical properties of aluminium alloy-alumina-boron carbide metal matrix composites. Materials \& Design, 2014, 58: 332-338.

[15] Rao V D P, Geethika V N, Krishnaveni P S. Multi-objective Optimization of Mechanical Properties of Aluminium 7075-Based Hybrid Metal Matrix
Composite Using Genetic Algorithm. Advances in 3D Printing \& Additive Manufacturing Technologies, 2017, 79-93.

[16] Shorowordi K M, Laoui T, Haseeb A S M A, et al. Microstructure and interface characteristics of $\mathrm{B}_{4} \mathrm{C}, \mathrm{SiC}$ and $\mathrm{Al}_{2} \mathrm{O}_{3}$ reinforced $\mathrm{Al}$ matrix composites: a comparative study. Journal of Materials Processing Technology, 2003, 142(3): 738-743.

[17] Chelladurai S J S, Arthanari R, Nithyanandam N, et al. Investigation of mechanical properties and dry sliding wear behaviour of squeeze cast LM6 aluminium alloy reinforced with copper coated short steel fibers. Transactions of the Indian Institute of Metals, 2018, 71(4): 813-822.

[18] Poddar P, Srivastava V C, De P K, et al. Processing and mechanical properties of $\mathrm{SiC}$ reinforced cast magnesium matrix composites by stir casting process. Materials Science and Engineering: A, 2007, 460: 357-364.

[19] Shankar S, Balaji A, Kawin N. Investigations on mechanical and tribological properties of Al-Si10-Mg alloy/sugarcane bagasse ash particulate composites. Particulate Science and Technology, 2018 36(6): 762-770.

[20] Ravi B, Naik B B, Prakash J U. Characterization of aluminium matrix composites $\left(\mathrm{AA6061} / \mathrm{B}_{4} \mathrm{C}\right)$ fabricated by stir casting technique. Materials Today, 2015, 2(4-5): 2984-2990.

[21] Karthikeyan A, Nallusamy S. Experimental analysis on sliding wear behaviour of aluminium-6063 with SiC particulate composites. International Journal of Engineering Research in Africa, 2017, 31: 3643.

[22] Bhushan R K, Kumar S, Das S. Fabrication and characterization of $7075 \mathrm{Al}$ alloy reinforced with SiC particulates. The International Journal of Advanced Manufacturing Technology, 2013, 65(5-8): 611-624.

[23] Amuda O S, Ibrahim A O. Industrial wastewater treatment using natural material as adsorbent. African Journal of Biotechnology, 2006, 5(16): 1483-1487.

[24] Jiang J, Wang Y. Microstructure and mechanical properties of the rheoformed cylindrical part of 7075 aluminum matrix composite reinforced with nano-sized SiC particles. Materials \& Design, 2015, 79: 32-41.

[25] Ilandjezian R, Gopalakannan S. Mechanical and Micro-Structural Behavior of Lignite Coal Based Fly-Ash and Microsphere Reinforced A 6061 Metal Matrix Composite. Applied Mechanics and Materials, 2016 852: 123-129.

[26] Ravindran P, Manisekar K, Narayanasamy P, et al. Application of factorial techniques to study the wear of Al hybrid composites with graphite addition. Materials \& Design, 2012, 39: 42-54.

[27] American Association of State Highway and Transportation Officials, \& American Society for Testing and Materials. E8M-04 Standard Test Methods for Tension Testing of Metallic Materials, ASTM International, West Conshohocken, PA, 2008

[28] Boopathi M M, Arulshri K P, Iyandurai N. Evaluation of mechanical properties of aluminium alloy 2024 reinforced with silicon carbide and fly ash hybrid metal matrix composites. American Journal of Applied Sciences, 2013, 10(3): 219.

[29] Rao T B. An experimental investigation on mechanical and wear properties of Al7075/SiCp composites: effect of SiC content and particle size. Journal of Tribology, 2018, 140(3): 031601-031601-8.

[30] Patidar D, Rana R S. Effect of $\mathrm{B}_{4} \mathrm{C}$ particle reinforcement on the various properties of aluminium matrix composites: a survey paper. Materials Today: Proceedings, 2017, 4(2): 2981-2988.

[31] Gireesh C H, Prasad K D, Ramji K, et al. Mechanical Characterization of Aluminium Metal Matrix Composite Reinforced with Aloe vera powder. Materials Today: Proceedings, 2018, 5(2): 3289-3297.

[32] Balasubramanian I, Maheswaran R. Effect of inclusion of SiC particulates on the mechanical resistance behaviour of stir-cast AA6063/ $\mathrm{SiC}$ composites. Materials \& Design, 2015, 65: 511-520.

[33] Ghandvar H, Farahany S, Idris M H. Effect of wettability enhancement of $\mathrm{SiC}$ particles on impact toughness and dry sliding wear behavior of compocasted A356/20SiC composites. Tribology Transactions, 2018, 61(1): 88-99. 